\title{
Design and Dynamic Performance Study on Hydrostatic Lubrication System of High-speed Precision Roller Grinding Head
}

Wu Huai-chao, Zhao Li-mei, Yan Wen-meng and Xu Lei

School of Mechanical Engineering, Guizhou University, Gui yang, 550025, China. Emeil: magoubs@sina.com, zlm0226@163.com,576732402@qq.com,2276043790@qq.com

To meet the need of high-speed steel roll grinding, a hydrostatic lubrication system for high-speed precision roller grinding head is designed and the dynamic performance of the system is simulated and analyzed in this study. The hydrostatic lubrication system was designed according to the lubrication characteristics of the eccentric sleeve and thrust bearing of the high-speed precision roller. Then the mathematical models of the main components of the system were established. And according to the schematic diagram of hydrostatic lubrication system, the dynamic performance of the lubrication system at high speed was simulated and tested. The simulation and experiment results show that the lubrication effect of the eccentric sleeve static chambers and thrust bearings is good, and the designed hydrostatic lubrication system is feasible.

Keywords: High-speed precision roller grinding head, AMESim, Lubrication system, Dynamic performance

\section{Introduction}

Due to the excellent toughness, hardenability, thermal stability and hot-cracking resistance of high speed steel, there is a tendency to replace the traditional rolls with high speed steel rolls in the steel industry. But because of the "wear resistance" of high speed steel, the traditional roller grinder within $45 \mathrm{mps}$ has low efficiency in grinding high speed steel rolls. The linear speed of the grinding wheel must be above $80 \mathrm{mps}$ to achieve high efficiency grinding [1]. Therefore, it is necessary to develop a high speed roller grinder for high speed steel roller grinding which the linear speed of the grinding wheel is above $80 \mathrm{mps}$. The increase of grinding head speed will cause the oil film temperature to rise and reduce the bearing capacity of oil film [2-4]. The oil film support will fail, and a case such as axle burning or axle suspension will occur when it is at high speed for a long time [5]. The oil film temperature rise, bearing capacity and other parameters are closely dependent on the oil supply lubrication system of the bearing [6-10]. Therefore, it is necessary to design a hydrostatic lubrication system to ensure the stable and full lubrication of the oil film supports.

In recent years, many scholars have done a lot of research on the design and dynamic performance of lubrication systems for different types of oil film bearings. Benoit Honel in the United States and Renaud Meillier in France established the simulation model of the lubrication system of the engine, and the performance of the lubrication system had been numerically simulated and calculated [11]. Liu Xueyuan and Huang Weiwei established the simulation model of diesel engine lubrication system, the distribution of pressure and flow rate of each oil film bearing in the system and the minimum film thickness and flow rate of oil film bearing under different working conditions were analyzed $[12,13]$. Yao Fang designed a kind of hydrostatic bearing of the roller press, and lubrication performances of bearing were studied by computational fluid dynamics and lubricating theory [14]. Yadav, Saurabh K. analyzed the influence of the shape on the sta- tic and dynamic performance characteristics of the hydrostatic thrust pad bearing system having Rabinowitsch fluid model lubricant [15]. Yu, XD et al. simulated the clearance flow characteristics of hydrostatic thrust bearing of large vertical CNC lathe [16]. Based on computational fluid dynamics and response surface method, Qianlei Peng et al presented a design method of gear transmission lubrication system to improve transmission efficiency [17]. However, there are few reports on the design and dynamic performance of hydrostatic lubrication system for high-speed precision roller grinder.

In view of the lubrication characteristics of the eccentric sleeve static chambers and thrust bearings of the highspeed precision roller grinding head, a hydrostatic oil supply lubrication system for the oil film support of the roller grinding head was designed. The simulation analysis and test of the hydrostatic lubrication system were carried out. Thus the lubrication effect of oil film bearing and the feasibility and reliability of the hydrostatic lubrication system were verified.

\section{Structure composition of High-speed Preci- sion Roller Grinding head}

To develop the hydraulic lubrication system, it is necessary to analyze the lubrication requirement of the high-speed roller grinder. Therefore, the structure principle of high-speed roller grinding head was analyzed firstly. The structure of the high-speed precision roller grinding head is as shown in Fig. 1. The grinding head is mainly composed of unloading device, pulley, front hybrid bearing, rear hybrid bearing, restrictors, thrust bearing, eccentric sleeve, grinding wheel chuck, box and so on. Adjustable hybrid oil film bearings are designed to support the spindle rotation. The hybrid bearings are formed by four cone ribbed slabs and the same taper bearing sleeve under the interference fit, thus forming eight wedge-shaped dynamic pressure oil chambers. In order to prevent the dry friction of the bearing during starting and stopping, four static chambers are established on the inner 
wall of the four ribbed slabs. The hydrostatic thrust bearings are designe and installed inside the eccentric sleeve to prevent the axial movement of the spindle. Guide bearing oil slots are slotted on the eccentric sleeve to prevent the loss of oil and oil pressure.

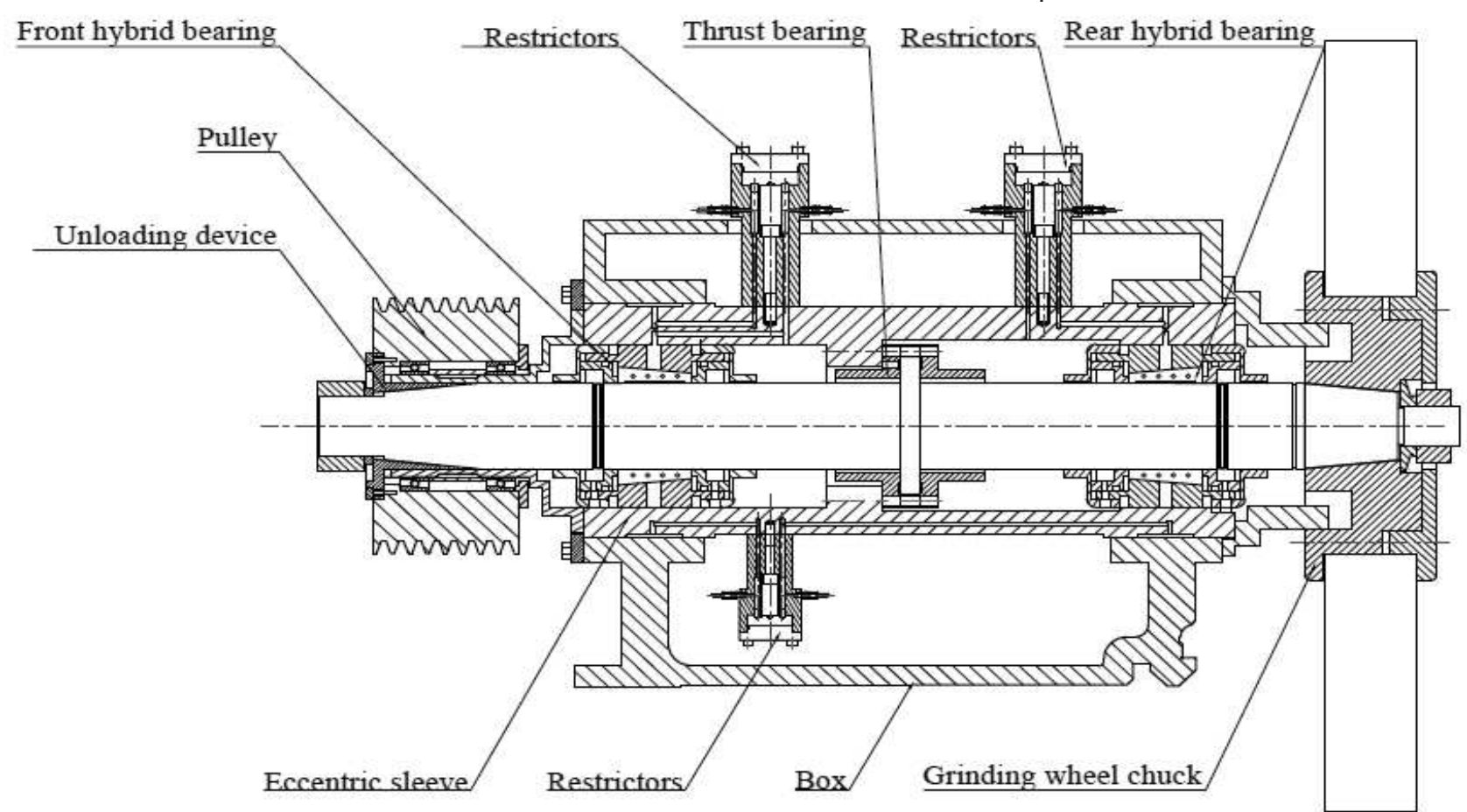

Fig. 1 Structure diagram of the high-speed precision roller grinding head

In the grinding head, oil film lubrications are required in the front and rear hybrid bearings, in thrust bearings and between the eccentric sleeves and the bed. Therefore, it is necessary to design a hydraulic lubrication system to realize oil film lubrication.

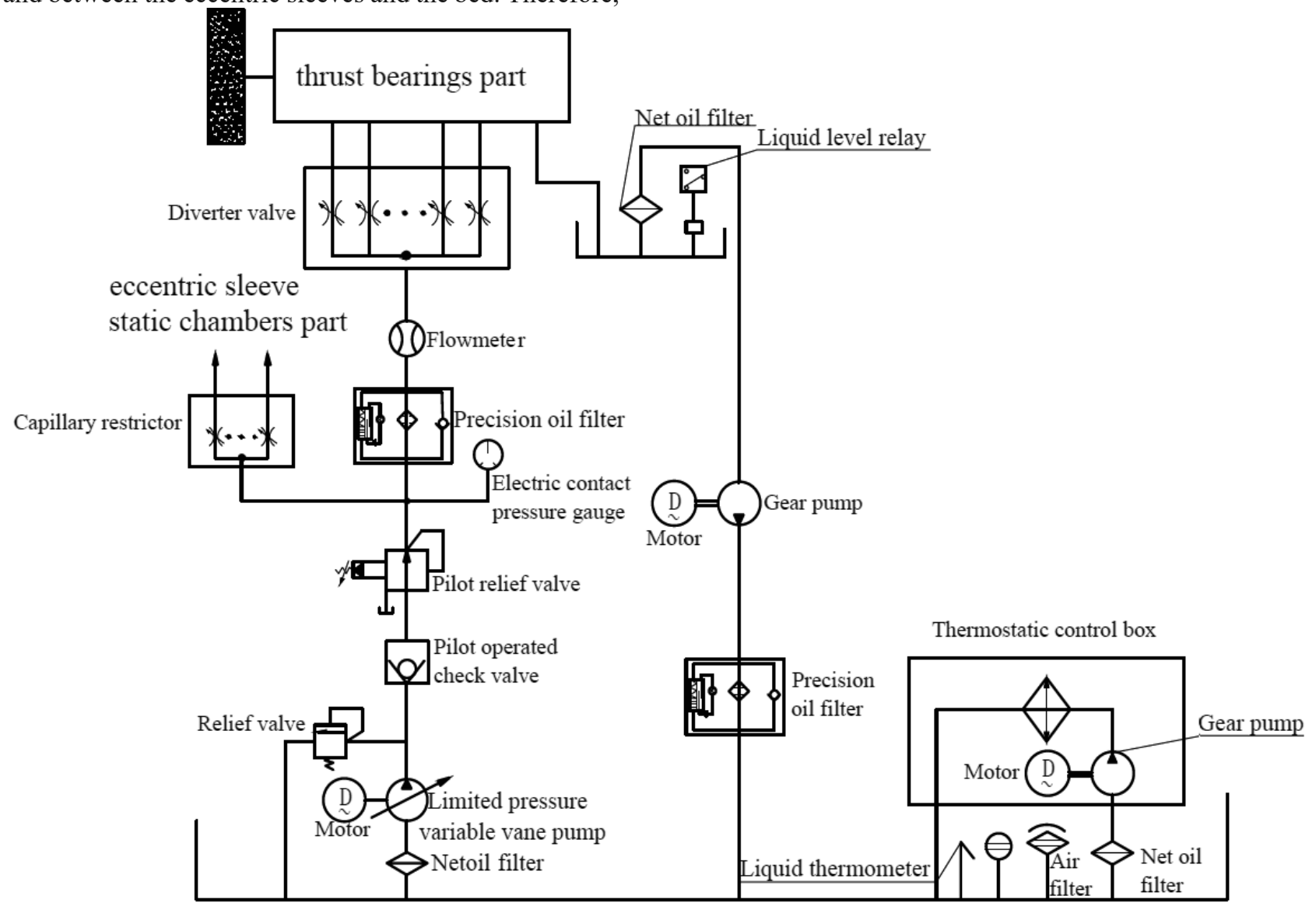

Fig. 2 Principle diagram of hydrostatic lubrication system for high-speed roller grinding head 


\section{Design on hydrostatic oil supply lubrication system for high-speed precision roller grin- ding head}

To prevent oil film bearings from mutual influences, the thrust bearings and eccentric sleeves were lubricated by an independent hydrostatic lubrication system as shown in Fig. 2. As there are so many oil supply holes in the bearing, a restrictor type constant pressure oil supply system was adopted. Limited pressure variable vane pump was used to supply oil. Via the pilot relief valve, the lubricating oil was reduced to the working pressure of the system. By the diverter valve, the oil film supports of the grinding head could be more effectively and steadily lubricated. The double filtration of oil by net oil filter and precision oil filter could meet the requirement of lubricating oil filtration accuracy for each oil film bearings. The level of the oil in the tank was monitored by the level relay, and the gear pump was controlled by PLC to pump the oil back to the return chamber of the tank intermittently, so as to ensure that the oil could be fully recycled.
The thermostatic control box weakened the influence on the stability of the oil supply system caused by the oil film temperature increment.

The application object of hydrostatic lubrication system in this paper is a high-speed precision roll grinder with grinding wheel speed of $60 \mathrm{mps}$. The roller grinder is a kind of grinder which was modified to adapt to the grinding of high speed steel rolls on the basis of the traditional roll grinder. The limit speed of the spindle is 2080 rpmin. The spindle system of the traditional roll grinder has always been lubricated with oil film, and this kind of bearing has shown good performance in industrial practice. At present, electromagnetic bearing has become an ideal bearing for high-speed spindle because of its advantages of no mechanical friction, no lubrication and low temperature rise, and has been more and more widely used. With the continuous development of spindle support technology of roll grinder, it will be possible for electromagnetic bearings to be gradually applied to this series of roll grinders.

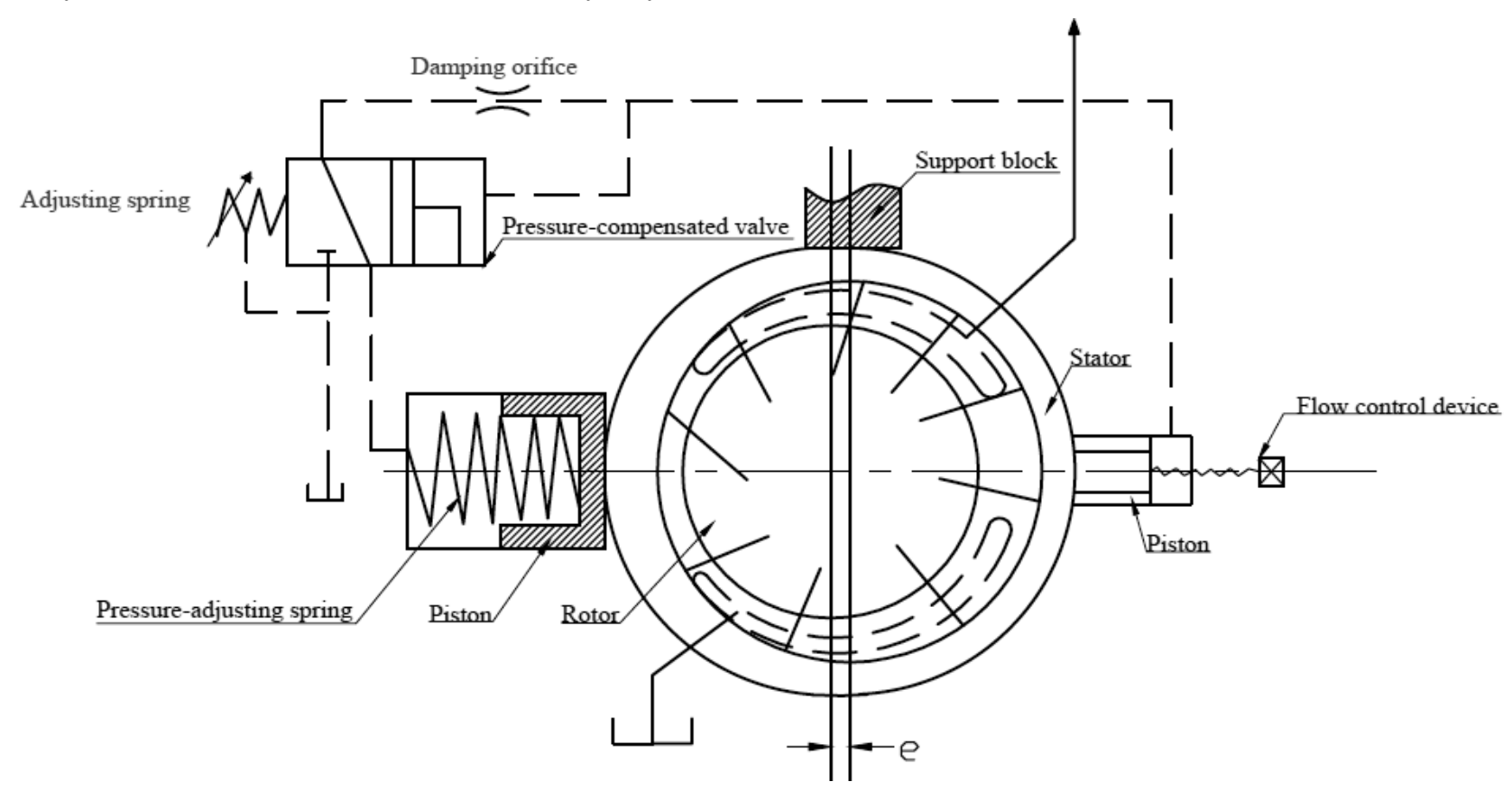

Fig. 3 principle diagram of external feedback variable vane pump

\section{Establishment of mathematical models for key hydraulic components}

\subsection{Establishment of mathematical model of limited pressure variable vane pump}

The working principle of the external feedback variable vane pump is shown in Fig. 3. According to the working principle of external feedback variable vane pumps, the relationship between the actual flow rate and the working pressure of the variable vane pump is as follows [18]:

$$
Q=K_{Q} e_{x}-K_{L} P
$$

where $K_{\mathrm{Q}}$ is the flow rate generated by the unit eccentricity, $e$ is unit eccentricity, $K_{\mathrm{L}}$ is the unit pressure leakage, and $n$ is the motor speed. When the pressure is less than the limited pressure $P_{\mathrm{c}}$, the stator is at the far right end, $e=e_{\max }$. Therefore, the equation of pressure versus flow is as follows:

$$
Q=K_{Q} e_{\max }-K_{L} P
$$

When $P$ is larger than the limited pressure $P_{\mathrm{c}}$, the eccentricity $e$ decreases gradually with the stator moving to the left, and the flow rate also decreases. When the output pressure is equal to the ultimate pressure $\left(P=P_{\max }\right)$, the output flow is zero. At this time, the suction flow of the vane pump will be used to compensate for leakage. Equation (3) can be obtained from equation (1).

$$
e_{\max }=\frac{K_{L}}{K_{Q}} P_{\max }
$$

When $P$ is between the limited pressure $P_{\mathrm{c}}$ and the ultimate pressure of the pump $P_{\max }\left(P<P_{\mathrm{c}}<P_{\max }\right)$, the equation of the force acting on the stator ring of the vane 
pump in the $\mathrm{x}$ direction is as follows:

$$
F_{k 0}-k_{s} e_{x}=A_{x}\left(P-P_{1}\right)
$$

where $A_{x}$ is the projection in the direction $x$ of the hydraulic pressure on the stator ring, $k_{\mathrm{s}}$ is the spring stiffness of the piston, $F_{\mathrm{k} 0}$ is the spring force of the piston with the eccentricity being zero, and $P_{1}$ is the back pressure of damping orifice.

The equation (1) and equation (4) were combined to eliminate $e_{x}$, and the flow rate of $P<P_{\mathrm{c}}<P_{\max }$ was obtained as follows:

$$
Q=\frac{K_{Q}}{K_{s}} F_{k 0}-\frac{K_{Q}}{K_{s}} P\left(A_{x} \frac{P-P_{1}}{P}+\frac{K_{s} K_{L}}{K_{Q}}\right)
$$

The equation (2) and equation (5) were combined to obtain the limited pressure $P_{\mathrm{C}}$.

$$
P_{c}=P_{1}+\frac{F_{k 0}-K_{s} e_{\max }}{A_{x}}
$$

\subsection{Establishment of mathematical model of diverter valve}

In this work, the 3FJLZ-L2-16 reversing piston diverter valve was selected, which was mainly composed of valve body, valve core, spring, fixed throttle ring, reversing piston, end cover and so on as shown in Fig. 3.

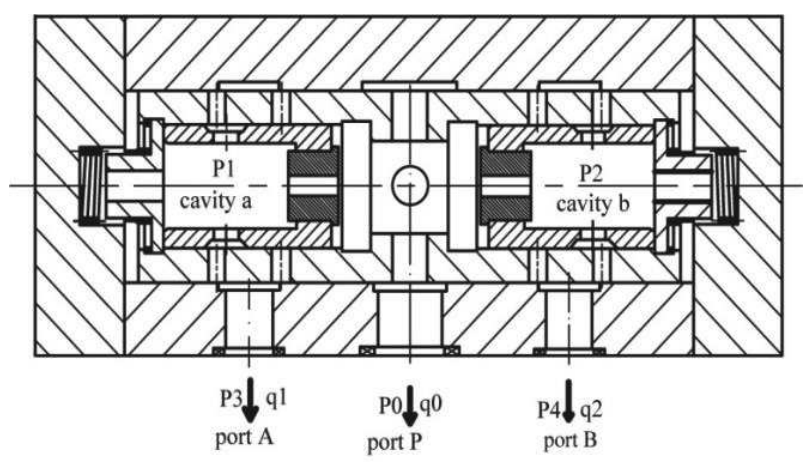

Fig. 3 Working diagram of reversing piston diverter valve

The working diagram of the diverter valve is shown in Fig. 3. In the figure, $\mathrm{P}$ is the oil inlet, $\mathrm{A}$ and $\mathrm{B}$ are the oil outlets, the two oil cavities a and b are connected to the left and the right spring cavities. The equilibrium equation for the forces acting on the main spool is as follows:

$$
\frac{\pi D_{f}^{2}}{4}\left(P_{1}-P_{2}\right)-F_{s 1}+F_{s 2}+k\left(x_{0}+\Delta x\right)=m_{f} \frac{d^{2} x}{d^{2} t}+B_{f} \frac{d x}{d t}
$$

where $P_{0}$ is pressure in the oil inlet of the diverter valve; $P_{1}$ and $P_{2}$ are pressure in the left and right cavities of the main spool; $F_{\mathrm{s} 1}$ and $F_{\mathrm{s} 2}$ are steady-state fluid forces of the left and right shunts. $D_{f}$ is the diameter of the main spool; $\Delta x$ is the displacement of the main spool; $x_{0}$ is the precompression amount of the spool spring; $m_{f}$ and $B_{f}$ are the flow rate of left and right fixed orifices of the main spool. In the equation, $F_{\mathrm{s} 1}$ and $F_{\mathrm{s} 2}$ are expressed as follows:

$$
\begin{aligned}
& F_{s 1}=2 \times 6 c_{1} c_{d 1} s_{1}(x) \cos \theta\left(P_{1}-P_{3}\right) \\
& F_{s 2}=2 \times 6 c_{2} c_{d 2} s_{2}(x) \cos \theta\left(P_{2}-P_{4}\right)
\end{aligned}
$$

where $S_{1}$ and $S_{2}$ represent the split area of the right and left side shunt ports of the spool; $C_{1}$ is a constant orifice flow coefficient; $C_{2}$ is the split area of the right and left side shunt ports of the spool. $C_{\mathrm{d} 1}$ and $C_{\mathrm{d} 2}$ are flow coefficients of the shunt ports, and $C_{\mathrm{d} 1}=C_{\mathrm{d} 2}$.

When the displacement of the spool is $\mathrm{x}$,

$$
\begin{gathered}
Q_{3}=6 c_{2} s_{1}(x) \sqrt{\frac{2}{\rho}\left(P_{1}-P_{3}\right)} \\
V_{1}=V_{0}+\frac{\pi D_{f}^{2}}{4} x
\end{gathered}
$$

Likewise,

$$
\begin{gathered}
Q_{2}-Q_{4}=\frac{V_{2}}{\beta} \frac{d P_{2}}{d t} \mp \frac{\pi D_{f}^{2}}{4} \frac{d x}{d t} \\
Q_{4}=6 c_{2} s_{2}(x) \sqrt{\frac{2}{\rho}\left(P_{2}-P_{4}\right)}
\end{gathered}
$$

where $Q_{1}$ and $Q_{2}$ represent the flow rate of the left and right side fixed orifices of the main spool, $Q_{3}$ and $Q_{4}$ are the flow rate of the left and right side shunt ports of the diverter valve, $V_{0}$ is the inlet volume of the diverter valve, $V_{1}$ and $V_{2}$ are the volume of the left and right side cavities of the main spool.

\section{Modeling and simulation of hydrostatic oil supply system for oil film supports}

\subsection{Establishment of Simulation Model of hydrostatic Lubrication system}

According to the structure characteristics, working principle and mathematical models, HCD library of AMESim was used to establish simulation models of variable vane pump and diverter valve. The VP-12-A3 type limited pressure variable vane pump with external feedback was used in this work. The modules of the limited pressure variable vane pump established mainly include: pressure regulating module, Vane pump oil suction module, the oil pressure cavity module, the input module of eccentricity and rotational speed, and the load control module. The commonly used hydraulic components can be modeled directly using the model provided by HYD library [19]. The system simulation model is as shown in Fig. 4.

\subsection{Simulation analysis of the oil film bearings lubri- cation}

The simulation analysis of the oil supply lubrication system was mainly focused on the pressure and flow of the bearings. Fig. 5 and Fig. 6 show the pressure and flow rate of the static chambers of the eccentricity sleeves and the thrust bearings at $2500 \mathrm{rpm}$. Because of the fluctuation of the output pressure of the variable vane pump, the working pressure of the limited pressure variable pump was adjusted to $10 \%-20 \%$ higher than the working pressure of the system, and then the lubricating oil was fed into bearings after the pressure was stabilized by the relief valve. From Fig. 5 (a) and (b), it can been seen that the pressure of the eccentric sleeve static chambers reaches the stable value at about $0.2 \mathrm{~s}$, the pressure is stable at about $25 \mathrm{bar}$, and the flow rate tends to be stable at $0.3 \mathrm{~s}$, the stable value of the flow rate in the front static chamber is $2.52 \mathrm{Lpm}$ and in the rear static chamber is $2.48 \mathrm{Lpm}$. 


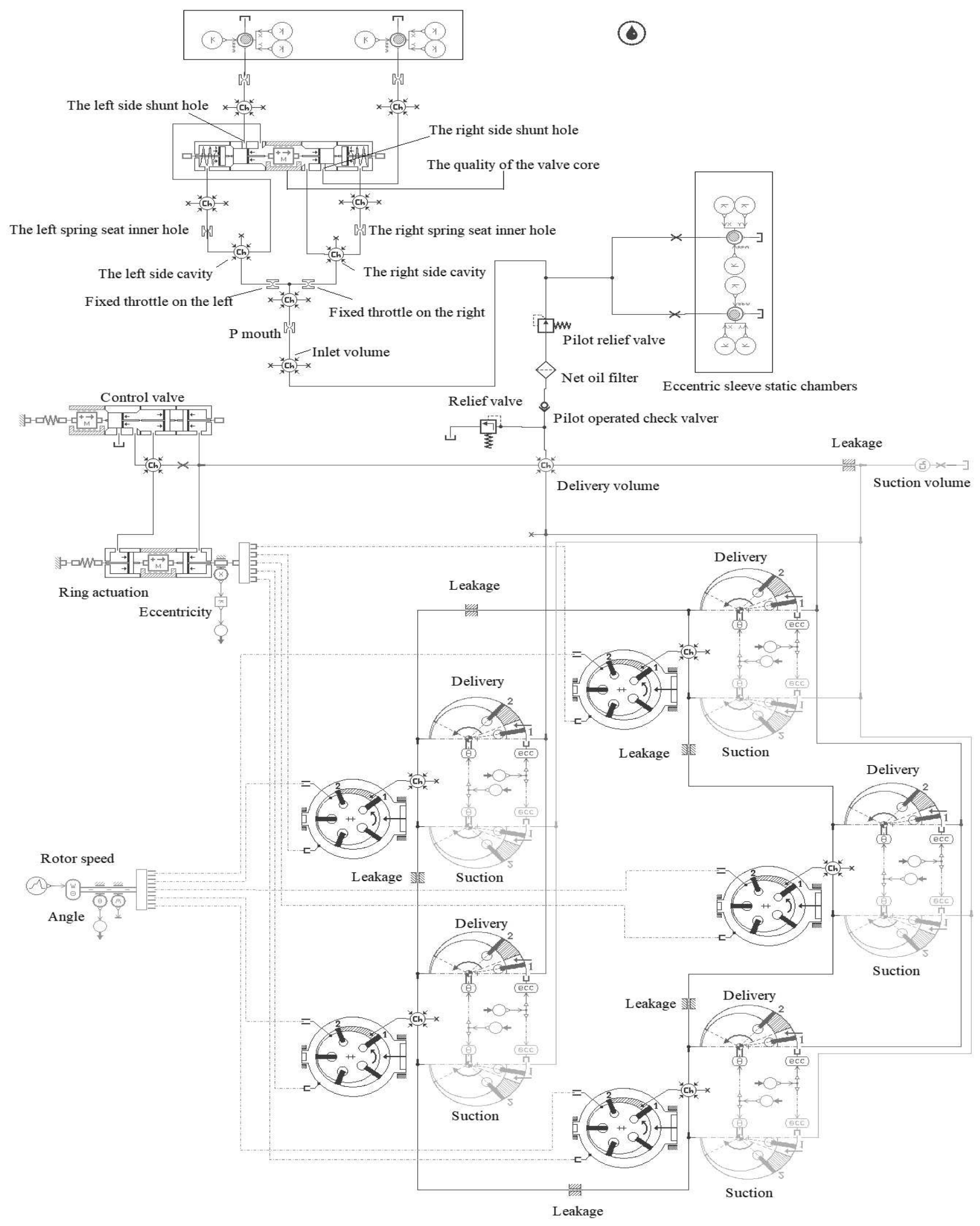

Fig. 4 Simulation model lubricating oil supply system

As shown in Fig. 6 (a) and (b), it can be seen that the pressure and flow rate of the two bearings are not equal at the initial moment. After about $0.2 \mathrm{~s}$, the pressure of the two bearings tends to be equal, and the flow rate is slightly fluctuated. This is because the load on the two bearings is not equal at the beginning. Under the action of the diverter valve, the pressure difference between the two outlet loads is gradually reduced, so that the outlet pressure and the flow rate are rebalanced. The pressure of the two thrust bearings is stable at 30 bars. After $0.5 \mathrm{~s}$, the flow rate fluctuates slightly around $3 \mathrm{Lpm}$, and the equivalent dividing can be basically realized under the action 
of the diverter valve. It can be seen that with the increase of the bearings speed, the load of the bearings increases accordingly, the pressure and the flow rate of the bearings also increase under the action of the limited pressure variable vane pump, so that the bearings can be lubricated fully and stably under different working conditions.

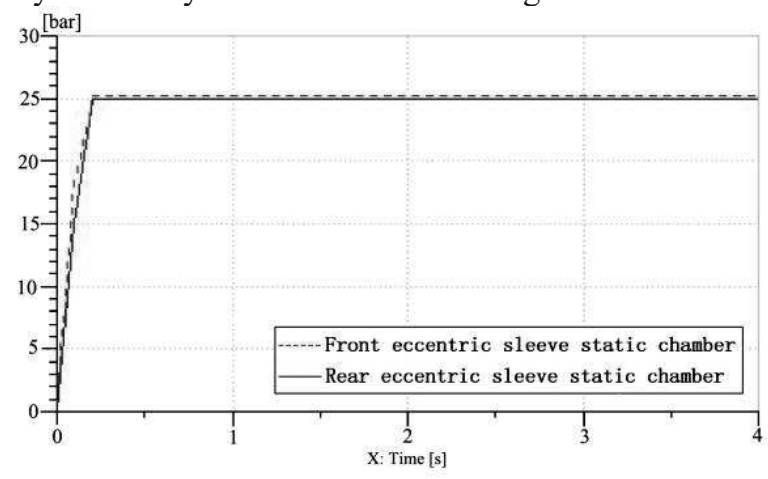

a) Pressure curves of eccentric sleeve static chambers

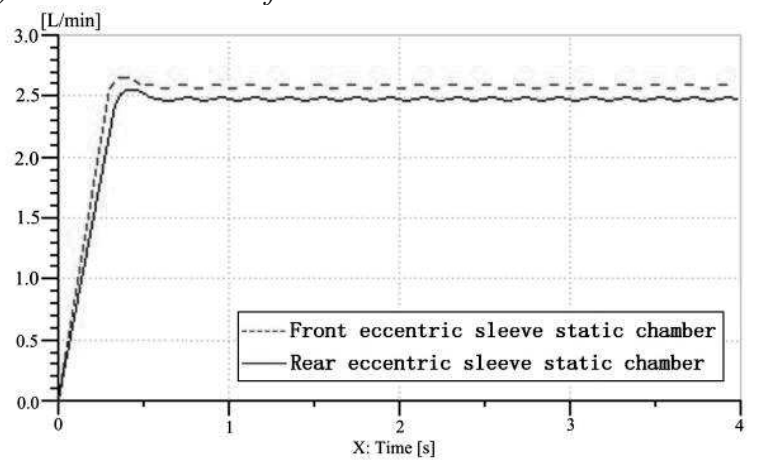

b) Flow curves of eccentric sleeve static chambers

Fig. 5 Pressure and flow rate curves of eccentric sleeve

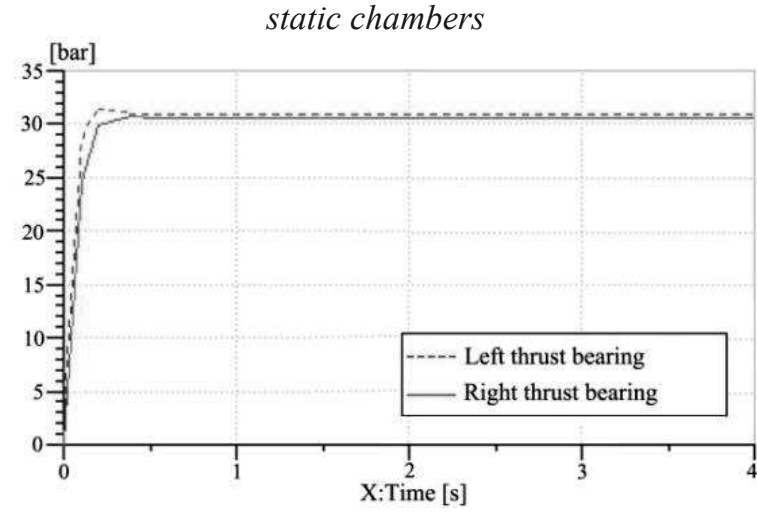

a) Pressure curves of thrust bearing static chambers

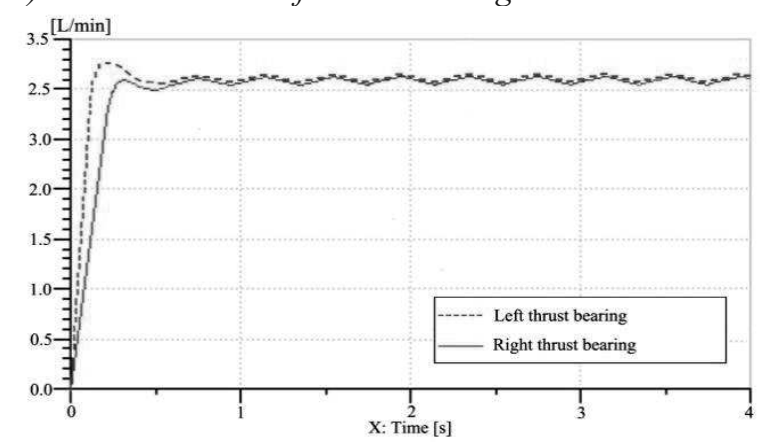

b) Flow rate curves of thrust bearing static chambers

Fig. 6 Pressure and flow rate curves of thrust bearings static chambers

\section{Development of experimental equipmen for hydrostatic lubrication system}

According to the hydrostatic lubrication system of 80 mps high-speed roller grinding head designed above, the experimental equipment was developed, as shown in Fig. 7. The working pressure of the limited pressure variable vane pump was set to be $10-20 \%$ higher than that of the system. Under the same conditions as the simulation, the pressure and flow rate of the eccentric sleeves and the static pressure chamber of the thrust bearings were measured. The experimental results were basically agree with the simulation results. Therefore, the feasibility and reliability of the hydrostatic lubrication system were further verified.

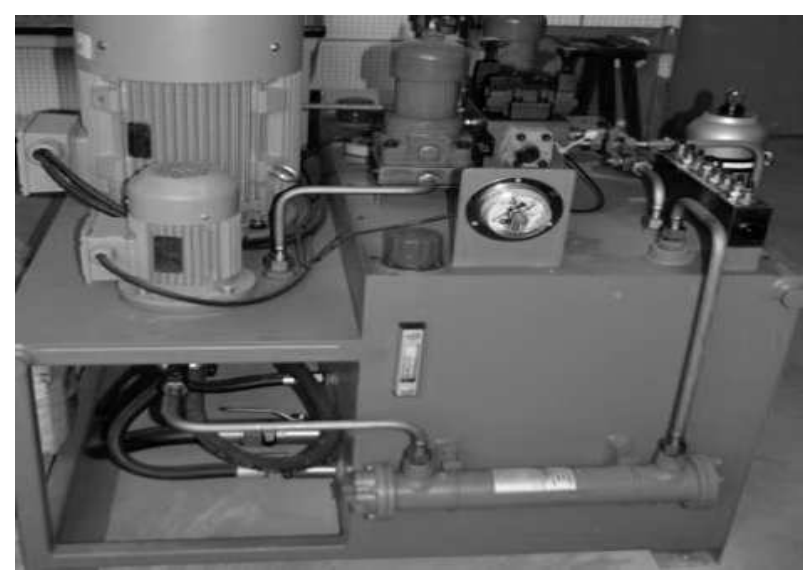

Fig. 7 Experimental equipment of hydrostatic lubrication system for $80 \mathrm{mps}$ high-speed roll grinding head

\section{Conclusion}

A hydrostatic lubrication system was designed for the static chambers of the eccentric sleeves and the thrust bearings for the $80 \mathrm{mps}$ high-speed precision roll grinding head. According to the structure principle of the main hydraulic components, the mathematical models were established, and the simulation model of the hydrostatic lubrication system was established by AMESim software.The simulation and experiment results of the hydrostatic lubrication system showed that with the increase of the bearings speed, the load of the bearings increased correspondingly. The pressure and flow rate of the bearings were also increased under the action of the limited pressure variable vane pump, so that the bearing could also be fully and steadily lubricated under different working conditions.

\section{Acknowledgment}

This project is supported by national natural science foundation of China (Grant No.51465008), preferred project of scientific and technological activities for personnel studying abroad in Guizhou Province (Grant No. Q.R.X.M.Z.Z.H.T (2018)0001), science and technology planning project in Guizhou Province (Grant No. Q.K.H.P.T.R.C[2017]5788), key research project on Innovation group in Guizhou Provincial Education De- 
partment (Grant No. Q.J.H. KY Z. [2018]011) and training plan for high-level innovative talent in Guizhou Province (Grant No. Q.K.H.P.T.R.C[2016] 5659).

\section{References}

[1] WU, HUAICHAO,WANG KUNPENG, SUN GUANCHAO, ZHAO LIMEI. (2018). Influence study of oil film thrust bearing on thermal characteristics of high-speed precision roll grinding head. In: Manufacturing Technology, Vol. 18, No.2, pp. 330-336.

[2] GUO LI. (2000). Research on hydrostatic sliding bearing and its supporting Spindle system, ShanXi: Xi'an Jiao Tong University.

[3] HARINGOVÁ, ANDREA,STRACÁR, KAROL,PRIKKEL, KAROL. (2016). Application of lubrication into the hip joint replacement. In: Manufacturing Technology, Vol. 16, No.3, pp. 502-506.

[4] SATISH C. SHARMA; SATISH C. JAIN; R. SINHASAN; P. L. SAH. (2001). Static and dynamic performance characteristics of orifice compensated hydrostatic flexible journal bearings with non-Newtonian lubricants. In:Tribology Transactions , Vol. 44, No. 2, pp. 242-248.

[5] WU HUAICHAO, ZHAO LIMEI, NI SILIANG, HE YONGYONG. (2019). Study on friction performance and mechanism of slipper pair under different paired materials in high-pressure axial piston pump. In: Friction, https://doi.org/10.1007/s40544-019-0314-2.

[6] CHUN S M. (2003). Network analysis of an engine lubrication system. In:Tribology international, Vol. 36, No. 8, pp. 609-617.

[7] PEXA, M., ALEŠ, Z.,PAVLŮ, J.,ČEDÍK, J.,(2015). Impact of viscosity of motor oil on the wear of plain bearings. In: Manufacturing Technology, Vol. 15, No.4, pp. 670-674.

[8] CHUN S M, PARK Y H, JANG S. (2000). A Study on Engine Lubrication System by Optimized Network Analysis-Part I: Case Study. In: $S A E$ Paper, 2000-01-2921.

[9] CHUN S M, PARK Y W. (2000). A Study on Engine Lubrication System By Optimized Network Analysis- Part II: Parametric Study. In: SAE Paper, 2000-01-2923.
[10] BENOIT HONEL, RENAUD MEILLIER, FREDERIC BRIX, et al. (2003). Model of an Engine Lubrication Circuit includingPredictive Bearing Components. In: SAE Paper, 2003-01-1965.

[11] LIU XUE-YUAN. (2007). Simulation and Experimental study on Lubrication system of D30 Diesel engine. YunNan: Kunming University of Science and Technology

[12] HUANGWEI-WEI. (2015). Simulation of Flow Characteristics on Lubricating System of a V type Multi-cylinder Diesel Engine. Beijing: Beijing Institute of Technology.

[13] Y FANG. (2012). Performance Study and Design of Hydrostatic Bearings on Roller Press. In: Lubrication Engineering, Vol. 37, No. 4, pp. 82-86.

[14] YADAV, SAURABH K.;SHARMA, SATISH C. (2014). Performance of hydrostatic tilted thrust pad bearings of various recess shapes operating with non-Newtonian lubricant. In: Finite Elements in Analysis and Design, Vol. 87, pp. 43-55.

[15] YU, XD; ZHANG, YQ; SHAO, JP, et al. (2009). Simulation Research on Gap Flow of Circular Cavity Multi-pad Hydrostatic Thrust Bearing. In: INTERNATIONAL CONFERENCE ON INTELLIGENT HUMAN-MACHINE SYSTEMS AND CYBERNETICS, Vol. 2, pp. 41.

[16] GOHARA M, SOMAYA K, MIYATAKE M, YOSHIMOTO S. (2014). Static characteristics of a water-lubricated hydrostatic thrust bearing using a membrane restrictor. In: Tribology International, Vol. 75, pp. 111-116.

[17] QIANLEI PENG, CHI ZHOU, LIANGJIN GUI, ZIJIE FAN. (2019). Investigation of the lubrication system in a vehicle axle: Numerical model and experimental validation. In: Proceedings of the Institution of Mechanical Engineers, Part D: Journal of Automobile Engineering, Vol. 233, No. 5, pp. 1232-1244.

[18] LIU JIAN. (2008). Research on Characteristic Analysis and Experiment of Pressure-limiting Variable Vane Pump. In: Journal of Mechanical Transmission, No. 3, pp. 86-88.

[19] JIN SHENG-QIU, CHENG KAI, WANG PENGYU. (2009). Analysizing the Capability and Improving the Structure of Synchronization Valve Based on AMESim. In: Chinese Hydraulics \& Pneumatic, No. 9, pp. 64-68. 